\title{
Imaging Expression of the Human Somatostatin Receptor Subtype-2 Reporter Gene with ${ }^{68}$ Ga-DOTATOC
}

\author{
Hanwen Zhang ${ }^{1}$, Maxim A. Moroz ${ }^{1}$, Inna Serganova ${ }^{1}$, Thomas $\mathrm{Ku}^{2}$, Ruimin Huang ${ }^{1}$, Jelena Vider ${ }^{1}$, Helmut R. Maecke ${ }^{3}$, \\ Steven M. Larson ${ }^{2,4}$, Ronald Blasberg ${ }^{1,2,4}$, and Peter M. Smith-Jones ${ }^{2}$ \\ ${ }^{1}$ Department of Neurology, Memorial Sloan-Kettering Cancer Center, New York, New York; ${ }^{2}$ Department of Radiology, Memorial \\ Sloan-Kettering Cancer Center, New York, New York; ${ }^{3}$ Department of Radiology, University Hospital Basel, Basel, Switzerland; and \\ ${ }^{4}$ Molecular Pharmacology and Chemistry Program, Memorial Sloan-Kettering Cancer Center, New York, New York
}

The human somatostatin receptor subtype 2 (hSSTr2)- ${ }^{68} \mathrm{Ga}-$ DOTATOC reporter system has several attractive features for potential translation to human studies. These include a low expression of hSSTr2 in most organs, a rapid internalized accumulation of ${ }^{68} \mathrm{Ga}$-DOTATOC in the SSTr2-expressing cells, and a rapid excretion of unbound radioligand by the renal system. We performed a series of in vitro and in vivo validation studies of this reporter system. Methods: A retroviral vector containing a dual reporter, pQCXhSSTr2-IRES-GFP (IRES: internal ribosome entry site; GFP: green fluorescent protein), was constructed and transduced into Jurkat, C6, and U87 cells. Stably transduced reporter cells were characterized in vitro using optical and radiometric methods. Multiple tumor-bearing mice were evaluated with ${ }^{68} \mathrm{Ga}-\mathrm{DOTATOC}$ PET studies. Results: The dual-reporter genes were incorporated into all tumor cell lines, and their expression levels were confirmed by fluorescence-activated cell sorting (FACS), GFP visualization, and reverse-transcriptase polymerase chain reaction (RT-PCR) analysis for hSSTr2. In vitro, hSSTr2 cell membrane expression was $36,000,280,000$, and $1,250,000$ copies per cell for the SSTR2-transfected Jurkat, U87, and C6 cell lines. Small-animal PET of ${ }^{68} \mathrm{Ga}$-DOTATOC in tumor-bearing mice demonstrated that the in vivo uptake of this radioligand was directly proportional to the in vitro expression of hSSTr2. The in vivo uptake of ${ }^{68} \mathrm{Ga}$-DOTATOC, at $2 \mathrm{~h}$ after injection, was low in all organs except the kidneys (7.8 percentage of injected dose per gram [\%ID/g]) and as high as $15.2 \% \mathrm{ID} / \mathrm{g}$ in transduced C6 tumors. The corresponding transduced-to-nontransduced tumor uptake ratio was 64 , and the tumor-to-muscle uptake ratio was around 500 . Conclusion: ${ }^{68} \mathrm{Ga}-\mathrm{DOTATOC}$ is an excellent specific ligand for this hSSTr2 reporter system and for hSSTr2 reporter gene PET. Because DOTATOC has undergone extensive clinical testing, this human reporter system has the potential for translation to human studies.

Key Words: reporter gene; hSSTr2; ${ }^{68} \mathrm{Ga}-\mathrm{DOTATOC}$; PET

J Nucl Med 2011; 52:123-131

DOI: 10.2967/jnumed.110.079004

\footnotetext{
Received May 12, 2010; revision accepted Sep. 23, 2010.

For correspondence or reprints contact: Ronald Blasberg, Departments of Neurology and Radiology, Memorial Sloan-Kettering Cancer Center, 1275 York Ave., New York, NY 10065

E-mail: blasberg@neuro1.mskcc.org

COPYRIGHT @ 2011 by the Society of Nuclear Medicine, Inc.
}

O omatostatin receptors (SSTrs) belong to a 7-transmembrane domain family of G-protein-coupled receptors. All 5 receptor subtypes are highly homologous between mice and humans and are expressed at relatively low levels in most organs. They are moderately expressed in the brain, gastrointestinal tract, pancreas, kidneys, and spleen. In contrast, SSTrs, especially SSTr2 (somatostatin receptor subtype 2 ), have been shown to be highly expressed in various human tumors, including pituitary, endocrine, pancreatic, and small cell lung tumors as well as in carcinoid tumors, paraganglioma, medullary thyroid carcinoma, and pheochromocytoma (1). These observations have led to radionuclide-based imaging and therapy of SSTr2-expressing tumors $(2,3)$.

Somatostatin and its numerous synthetic derivatives have a wide spectrum of physiologic functions. These ligands act as neurotransmitters, paracrine or autocrine regulators, or systemic regulators of cell secretion, neuromodulation, smooth muscle contractility, nutrient absorption, and cell growth (4). In tumors, somatostatin and somatostatin agonists indirectly control cell growth in vivo through inhibition of the release of growth-promoting hormones (5). Somatostatin can also act through antiangiogenic mechanisms (6) involving the inhibition of proliferation and migration of endothelial cells and monocytes (7) or by interfering with the production of proangiogenic factors from tumor cells (8). Moreover, direct antiproliferative activity in both normal and tumor cells, in which one of the main intracellular pathways responsible was the modulation of phosphotyrosine phosphatase, has also been reported (9).

Octreotide is a metabolically stable somatostatin inhibitory peptide, originally developed for the symptomatic treatment of patients with metastatic carcinoid tumors. Octreotide binds with a low nanomolar affinity to hSSTr2 and hSSTr5, with moderate affinity to hSSTr3 (200 nM), and with poor affinity to hSSTr1 and hSSTr4 (>1,000 nM) (10). ${ }^{111}$ In-diethylenetriaminepentaacetic acid (DTPA)-octreotide was subsequently developed as an hSSTr imaging agent and is approved by the Food and Drug Administration (FDA) for SPECT of neuroendocrine tumors (2). 
DOTATOC was subsequently developed for labeling with ${ }^{90} \mathrm{Y}$ or ${ }^{177} \mathrm{Lu}$ and was initially used for targeted radiotherapy. Clinical trials (phase II/III) have been performed in many European centers (3). DOTATOC has also gained widespread use as a PET agent when chelated with ${ }^{68} \mathrm{Ga}(11,12)$. In addition, other PET nuclides, including ${ }^{94 \mathrm{~m}} \mathrm{Tc},{ }^{18} \mathrm{~F},{ }^{86} \mathrm{Y}$, and ${ }^{64} \mathrm{Cu}$, have been coupled to octreotide or similar somatostatin analogs for quantitative PET of hSSTr2 expression. The preclinical or clinical validation of these radiolabeled somatostatin derivatives, some of which are currently used in clinical studies, indicates that the hSSTr2-radiolabeled ligand combination could be used for transgene imaging in patients.

The hSSTr2 gene has been incorporated into a replication-incompetent adenoviral vector (Ad-CMVhSSTr2) and used as a radionuclide-based reporter gene for noninvasive imaging of xenografts (13). However, the radioligands (FDAapproved ${ }^{111}$ In-DTPA-octreotide $(14,15),{ }^{99}$ Tc-labeled P829 (16), and ${ }^{94 \mathrm{~m}} \mathrm{Tc}$-demotate 1 (17)) that have been used to image hSSTr2 expression target several SSTrs and produce comparatively poor-quality images. The relatively high background radioactivity and moderate transducedto-nontransduced tumor uptake ratios have limited the clinical translation of hSSTr2 reporter gene imaging since the original reports in 1999 (14).

To further investigate hSSTr2 as a potential reporter gene of human origin, we constructed a constitutively expressing dual-reporter retroviral vector (pQCXhSSTr2-IRES-GFP; IRES: internal ribosome entry site, GFP: green fluorescent protein), transduced several cell lines with this reporter, and chose ${ }^{67 / 68} \mathrm{Ga}$-DOTATOC as the radioligand for in vitro validation and in vivo imaging. We chose ${ }^{67 / 68}$ Ga-DOTATOC because of its high and selective affinity for the hSSTr2 receptor and because of the high-quality, low-background PET images that have been obtained in patients with neuroendocrine tumors. The focus of the current study was to investigate the feasibility of imaging hSSTr2 reporter gene expression with ${ }^{68} \mathrm{Ga}$-DOTATOC in mice to obtain preclinical data in support of future studies in patients.

\section{MATERIALS AND METHODS}

\section{General}

All chemicals were obtained from commercial sources and used without further purification. DOTATOC and gallium-DOTATOC were synthesized as reported earlier (18). ${ }^{67} \mathrm{GaCl}_{3}$ was purchased from MDS Nordion, and ${ }^{68} \mathrm{GaCl}_{3}$ was eluted from a commercial ${ }^{68} \mathrm{Ge} /{ }^{68} \mathrm{Ga}$ generator (Cyclotron Co Ltd.). U87, C6, and Jurkat cell lines were obtained from American Type Culture Collection and propagated as recommended. Chinese hamster ovary (CHO) cells selectively transfected with hSSTr1, hSSTr2, hSSTr3, and hSSTr4 were kindly provided by Dr. Friedrich Raulf of Novartis. Radioactivity was quantified with a Wizard 3" $1480 \gamma$-counter (PerkinElmer) or a dose calibrator (CRC-30BC; Capintec).

\section{Plasmid Construction and Cell Transduction}

The pQCXhSSTr2-IRES-GFP retroviral vector was developed using an approach similar to that described for the pQCXhNETIRES-GFP retroviral vector (19). Briefly, to construct the
pQCXhSSTr2-IRES-GFP vector, cDNA for SSTr2 was amplified from the construct kindly provided by Dr. Graeme Bell (University of Chicago). The resulting polymerase chain reaction (PCR) product was used for ligation into the pQCX-IRES-GFP backbone to obtain the final plasmid where the gene SSTr2 was separated from the GFP by an IRES element.

U87, C6, and Jurkat cell lines were transduced with the pQCXhSSTr2-IRES-GFP retroviral vector. Briefly, the DNA of vector-encoding plasmid $(10 \mu \mathrm{g})$ was transfected into the GPG29 packaging cell line using LipofectAMINE 2000 (Invitrogen). All cell lines were stably transduced by incubating $50 \%$ confluent cell cultures with a virus-containing medium for $12 \mathrm{~h}$ in the presence of polybrene ( $8 \mathrm{mg} / \mathrm{mL}$; Sigma). Cells were sorted using a fluorescence-activated cell sorter (BD Bioscience).

\section{Semiquantitative Reverse-Transcriptase PCR Analysis}

Total RNA was isolated using TRIzol reagent (Invitrogen) and treated with RNase-free DNase I (AmBion) according to the manufacturer's instructions. The following primer sets were used for cDNA synthesis (Promega):

\section{hSSTr2 gene: (F) 5'-GTCACCCGAATGGTGTCCATC-3'; (R) 5'-ATTTGTCCTGCTTACTGTCACTC-3'; GFP gene: (F) 5'-CCCTCGTGACCACCCTGACCT-3'; (R) 5'-CCATGTGATCGCGCTTCTCGT-3'; $\beta$-actin gene: (F) 5'-TGGTGGGCATGGGTCAGAAGGAT-3'; (R) 5'-CTAGAAGCATTTGCGGTGGACGAT-3'.}

\section{${ }^{68 / 67} \mathrm{Ga}$-DOTATOC Radiosynthesis}

${ }^{68} \mathrm{Ga}$-DOTATOC was synthesized by mixing $200 \mu \mathrm{L}$ of the ${ }^{68} \mathrm{Ga} /{ }^{68} \mathrm{Ge}$ generator eluate $(0.1 \mathrm{M} \mathrm{HCl})$ with $10 \mu \mathrm{L}$ of DOTATOC (10 nmol) and $40 \mu \mathrm{L}$ of $1.0 \mathrm{M} \mathrm{NH}_{4} \mathrm{OAc}(\mathrm{pH} \mathrm{3.8)}$ for $10-12 \mathrm{~min}$ at $95^{\circ} \mathrm{C}$. The radioligand was purified from unchelated ${ }^{68} \mathrm{Ga}$ using a SepPak $\mathrm{C}_{18}$ cartridge (Waters) preconditioned with $5 \mathrm{~mL}$ of ethanol and $10 \mathrm{~mL}$ of $\mathrm{H}_{2} \mathrm{O}$. Unchelated ${ }^{68} \mathrm{Ga}$ and $\mathrm{NH}_{4} \mathrm{OAc}$ buffer were eluted with $5 \mathrm{~mL}$ of $\mathrm{H}_{2} \mathrm{O}$, and ${ }^{68} \mathrm{Ga}$-DOTATOC was eluted with $3 \mathrm{~mL}$ of ethanol. Final quality control of the radioligand was performed by high-performance liquid chromatography using a Jupiter $\mathrm{C}_{18}$ column (Phenomenex) with an eluent of $0.05 \%$ trifluoroacetic acid/MeCN gradient (0-15 $\mathrm{min}, 9.5 \%-47.5 \% \mathrm{MeCN}$; 16-19 $\mathrm{min}, 95 \% \mathrm{MeCN}$; and $19-20 \mathrm{~min}, 9.5 \% \mathrm{MeCN}) .{ }^{67} \mathrm{Ga}-$ DOTATOC was prepared similarly.

\section{Uptake and Dissociation of ${ }^{67} \mathrm{Ga}$-DOTATOC in hSSTr2-Transduced Cells}

Uptake Studies. Multiple samples containing approximately 1.0 $\mathrm{kBq}$ of ${ }^{67} \mathrm{Ga}$-DOTATOC $(1.6 \mathrm{pmol})$ were incubated with $1.0 \times 10^{6}$ cells suspended in a total volume of $0.5 \mathrm{~mL}$ of phosphate-buffered saline (1.0 mM Ca(II), $0.5 \mathrm{mM} \mathrm{Mg(II)).} \mathrm{The} \mathrm{samples} \mathrm{were} \mathrm{gently}$ shaken at $24^{\circ} \mathrm{C}$ or $37^{\circ} \mathrm{C}$ for between $5 \mathrm{~min}$ and $4 \mathrm{~h}$. At various time points, triplicate samples were isolated by rapid filtration through a glass microfiber filter (934-AH; Whatman) and washed with $3 \times 2 \mathrm{~mL}$ of ice-cold tris-buffered saline $(\mathrm{pH} 7.4)$ and assayed for radioactivity.

Dissociation Studies. hSSTr2-transduced cells were incubated as described in the previous section for either 0.25 or $1 \mathrm{~h}$ before a 300 -fold excess of gallium-DOTATOC $(0.5 \mathrm{nmol})$ was added. At various times, the cells were isolated and the radioactivity measured as described in the previous section. 
The resultant uptake data were expressed as ${ }^{67} \mathrm{Ga}$-DOTATOC molecules per cell and plotted as a function of time.

\section{Binding Affinity of natGa (Gallium)-DOTATOC and hSSTr2 Expression Level}

Saturation binding studies were performed using ${ }^{67} \mathrm{Ga}$-DOTATOC and varied concentrations of gallium-DOTATOC. Briefly, triplicate samples containing $1.0 \times 10^{6}$ cells and $0.1-500$ pmol of ${ }^{67 / n a t}$ Ga-DOTATOC $(\sim 1 \mathrm{kBq})$ in $0.5 \mathrm{~mL}$ of $1 \%$ bovine serum albumin/phosphate-buffered saline $(1.0 \mathrm{mM} \mathrm{Ca}(\mathrm{II})$ and $0.5 \mathrm{mM}$ $\mathrm{Mg}(\mathrm{II}), \mathrm{pH} 7.4)$ were incubated at $37^{\circ} \mathrm{C}$ (C6-SSTr2) or room temperature. After an incubation of $60 \mathrm{~min}$, the cells were isolated by rapid filtration through glass microfiber filters and washed with $3 \times 2 \mathrm{~mL}$ of ice-cold tris-buffered saline $(\mathrm{pH}$ 7.4). The cell uptake was calculated as molecules per cell. The data were plotted as a function of gallium-DOTATOC concentration, and the dissociation constant $\left(\mathrm{K}_{\mathrm{d}}\right)$ and maximum number of binding sites $\left(\mathrm{B}_{\max }\right)$ per cell were estimated using a least-squares fitting routine (GraphPad Prism 5; GraphPad Software).

\section{hSSTr2-Mediated ${ }^{67} \mathrm{Ga}$-DOTATOC Uptake in hSSTr-Expressed or Wild-Type (WT) Cells}

The specific accumulation of ${ }^{67} \mathrm{Ga}$-DOTATOC was studied (with an approach similar to the one used for the uptake and dissociation studies) using hSSTr-transduced cells and corresponding WT cells. The incubation was $2 \mathrm{~h}$ at $37^{\circ} \mathrm{C}$. One nanomole of galliumDOTATOC or somatostatin-14 was used for blocking.

\section{Small-Animal PET ${ }^{68}$ Ga-DOTATOC Imaging}

All animal experiments were approved by the Institutional Animal Care and Use Committee of Memorial Sloan-Kettering Cancer Center. Male athymic $n u / n u$ mice (age, 8 wk; Harlan) were pretreated with 4.5 Gy of external irradiation $24 \mathrm{~h}$ before subcutaneous implantation of tumor cells. Cells were suspended in $200 \mu \mathrm{L}$ of cell culture medium or, in the case of Jurkat cells, $200 \mu \mathrm{L}$ of $50 \%$ Matrigel (BD Bioscience). One group of animals was injected with $8 \times 10^{6}$ C6 cells and $8 \times 10^{6}$ U87 (both WT and SSTr2-transduced). A second group of animals received $15 \times 10^{6}$ Jurkat cells (WT and SSTr2-transduced), followed 3 wk later by $8 \times 10^{6}$ C6-SSTr 2 and $8 \times 10^{6}$ U87-SSTr 2 cells. Nine to $14 \mathrm{~d}$ after the final inoculation, small-animal PET and tissue sampling were performed.

For the small-animal PET and biodistribution studies, ${ }^{68} \mathrm{Ga}-$ DOTATOC (3.7-11.4 MBq, $1.0 \mathrm{nmol})$ was injected into the penile vein of the anesthetized mouse ( $2 \%$ isoflurane). Small-animal PET was performed at 1 and $2 \mathrm{~h}$ after injection on an R4 microPET scanner (Concorde Microsystems), with the tumors centered in the field of view. Ten-minute scans were acquired, with an energy window of $250-750 \mathrm{keV}$ and a coincidence timing window of 6 ns. Region-of-interest analysis of the acquired images was performed using ASIPro software (Siemens), and the observed maximum pixel value was corrected for partial-volume effects based on the size of the tumor.

Directly after the last small-animal PET study, the mice were euthanized by $\mathrm{CO}_{2}$ inhalation, and the organs of interest were removed, weighed, and counted in a $\gamma$-counter, along with a known volume of the injectate. Data were expressed as \% ID/g.

\section{In Vivo Fluorescence Imaging}

Tumor-bearing mice were anesthetized with $2 \%$ isoflurane and imaged on a Maestro imager (Cambridge Research Instruments) running Maestro Imaging Software (version 2.4), as described previously (20). GFP images were acquired at 445- to 490-nm excitation and using a 515-nm long-pass emission filter at f/11 for $300 \mathrm{~ms}$. For spectral deconvolution, an image matrix was collected on the Maestro, with excitation at 445-490 nm, and 110 emission images were acquired in 2-nm steps between 500 and 720. Fluorescence region and autofluorescence regions were identified and spectrally unmixed using the instrument's software.

\section{Statistical Analysis}

The statistical significance of differences between mean values was determined using the Student $t$ test. $P$ values less than 0.05 were considered to be statistically significant.

\section{RESULTS}

\section{Generation of hSSTr2-GFP Reporter Cells}

A retroviral vector (pQCXhSSTr2-IRES-GFP) encoding both $h S S T r 2$ and GFP genes was constructed (Supplemental Fig. 1A; supplemental materials are available online only at http://jnm.snmjournals.org) and used to transduce Jurkat, U87, and C6 cells. Stably transduced cell lines were obtained after FACS-sorting based on GFP expression (Supplemental Figs. 1B and 1D). U87- and C6-transduced cells expressed a significantly higher level of GFP expression than did Jurkat cells. After FACS purification, more than $95 \%$ of C6 and U87 cells were GFP-positive, whereas only $80 \%$ of Jurkat cells expressed GFP (Supplemental Fig. 1B). hSSTr2 and GFP expression was confirmed by RT-PCR (Supplemental Fig. 1C) and fluorescence microscopy (Supplemental Fig. 1D).

\section{${ }^{68 / 67} \mathrm{Ga}$-DOTATOC Radiosynthesis}

The ${ }^{68}$ Ga-DOTATOC was synthesized within 30 min with a specific activity of approximately $19 \mathrm{GBq} / \mu \mathrm{mol}(60 \%$ radiochemical yield, uncorrected). ${ }^{67} \mathrm{Ga}$-DOTATOC was prepared using a similar method, with radiochemical yields of $98 \%$ and a specific activity of more than $9 \mathrm{GBq} / \mu \mathrm{mol}$.

\section{Uptake and Dissociation of ${ }^{67} \mathrm{Ga}$-DOTATOC in hSSTr2-Transduced Cells}

${ }^{67}$ Ga-DOTATOC showed a specific time- and temperature-dependent uptake in the hSSTr2-tranduced cells (C6, U87, and CHO) (Fig. 1). The uptake in all 3 cell lines at $37^{\circ} \mathrm{C}$ was significantly higher than that at $24^{\circ} \mathrm{C}(P<0.022)$ after a 4-h incubation. ${ }^{67} \mathrm{Ga}$-DOTATOC displayed a rapid uptake in the C6-SSTr2 cells at $37^{\circ} \mathrm{C}$ and reached an apparent equilibrium within $30 \mathrm{~min}$. The kinetic displacement studies showed a similar displacement of radioactivity from cells preincubated for 0.25 and $1 \mathrm{~h}$, indicating that radiolabeled DOTATOC was not internalized at $37^{\circ} \mathrm{C}$. The same study performed at $24^{\circ} \mathrm{C}$ showed that equilibrium binding was not reached within $4 \mathrm{~h}$ of incubation and showed similar low levels of undisplaced cell-bound radioactivity.

Interestingly, the kinetic binding studies with U87-SSTr2 cells showed more rapid equilibrium when performed at $24^{\circ} \mathrm{C}$ than at $37^{\circ} \mathrm{C}$, consistent with the displacement studies performed at $37^{\circ} \mathrm{C}$. This finding suggests that a large fraction of radiolabeled DOTATOC was being internalized.

The kinetic binding studies with CHO-SSTr2 cells showed similar rates of equilibrium binding whether performed at 
FIGURE 1. Kinetics of ${ }^{67} \mathrm{Ga}-\mathrm{DOTATOC}$ binding to and dissociation from hSSTr2 expressed by transduced cells. Dissociation of ligand-receptor complex was initiated by addition of excess natGa-DOTATOC after 0.25 and $1 \mathrm{~h}$. Results (mean $\pm \mathrm{SD}$ ) are from $2-4$ independent studies. Solid line $=37^{\circ} \mathrm{C}$; dotted line $=24^{\circ} \mathrm{C}$.

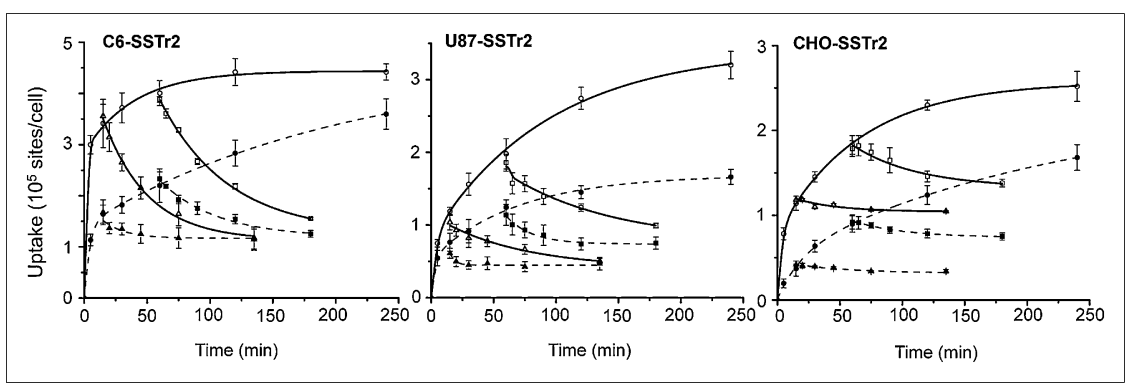

$24^{\circ} \mathrm{C}$ or $37^{\circ} \mathrm{C}$. However, the displacement studies showed considerably higher levels of DOTATOC internalization at $37^{\circ} \mathrm{C}$.

\section{hSSTr2 Expression Level and Binding Affinity of natGa-DOTATOC}

On the basis of the kinetic profiles (Fig. 1), the experimental conditions were optimized to determine the $\mathrm{K}_{\mathrm{d}}$ value and $\mathrm{SSTr} 2$ expression level $\left(\mathrm{B}_{\max }\right)$ in each of the transduced cell lines. These data are listed in Table 1. A typical saturation binding curve and Scatchard transformation plot for each transduced cell line is shown in Supplemental Figure 2. The $K_{d}$ values for all 4 SSTr2-transduced cell lines were similar, approximately 5-7 nM. The Scatchard transformations were all linear, indicating a single class of high-affinity binding sites for ${ }^{67} \mathrm{Ga}$-DOTATOC. The rank order for hSSTr2 expression was C6-SSTr2 > > U87SSTr $2 \approx$ CHO-SSTr2 $>>$ Jurkat-SSTr2 cells (Table 1 ). Repeated SSTr2 binding site assays and FACS analysis in hSSTr2/GFP-transduced CHO cells showed no significant change in the number of binding sites per cell or FACS profile over a 20 -mo period.

\section{${ }^{67}$ Ga-DOTATOC Uptake in hSSTr-Transduced and WT Cells}

The uptake of ${ }^{67} \mathrm{Ga}$-DOTATOC in hSSTr2-transduced cells was significantly higher than that in corresponding WT (nontransduced) cells (Fig. 2A). The calculated transduced-to-WT ratios ranged from $8.1 \pm 1.7$ (Jurkat) to $108 \pm$ 15 (C6). These results are consistent with the $\mathrm{B}_{\max }$ estimates (Table 1); a good correlation between the cell uptake values and $\mathrm{B}_{\max }$ estimates was obtained (Fig. 2B). Little or no ${ }^{67} \mathrm{Ga}$-DOTATOC was accumulated in $\mathrm{CHO}$ cells transduced with the hSSTr1, hSSTr3, or hSSTr4 genes (Fig. 2A). In addition, the uptake of ${ }^{67} \mathrm{Ga}$-DOTATOC in SSTr2-transduced cell lines was substantially blocked $(>90 \%)$ with a 1,000 fold excess of gallium-DOTATOC or somatostatin-14 (Fig. $2 \mathrm{~A})$. These results demonstrated the high specificity of ${ }^{67} \mathrm{Ga}-$ DOTATOC binding to the human SSTr2 receptor and the low natural expression of SSTr2 or SSTr5 in the WT cells.

\section{${ }^{68} \mathrm{Ga}-\mathrm{DOTATOC}$ Biodistribution and Imaging}

Small-animal PET images of ${ }^{68} \mathrm{Ga}$-DOTATOC uptake in hSSTr2-transduced and WT xenografts were obtained at 1 and $2 \mathrm{~h}$ after injection of the tracer (Fig. 3). The hSSTr2transduced xenografts were clearly visualized and distinct from both adjacent background radioactivity and WT xenografts in the projection images (Figs. 3A and 3B). Coronal and sagittal slices distinctly show the hSSTr2 xenografts, kidneys, and bladder. GFP-fluorescence imaging also visualized the SSTr2-IRES-GFP-transduced xenografts but not WT tumors (Fig. 3B), consistent with the radiotracer-based in vivo imaging. As expected, the kidneys and bladder were not seen in the fluorescence images, whereas the smallanimal PET images reflect the dominant renal clearance of ${ }^{68} \mathrm{Ga}$-DOTATOC from the body.

The ${ }^{68} \mathrm{Ga}$-DOTATOC organ uptake levels $(\% \mathrm{ID} / \mathrm{mL})$ were obtained by region-of-interest analysis of the small-animal PET images and corrected for partial-volume effects. Xenograft uptake was similar at 1 and $2 \mathrm{~h}$ after injection, demonstrating rapid in vivo binding of ${ }^{68} \mathrm{Ga}$-DOTATOC to hSSTr2 receptors in these animal xenografts (Fig. 4A). The rank order of ${ }^{68} \mathrm{Ga}$-DOTATOC accumulation was C6-SSTr2 $>$ U87-SSTr2 > Jurkat-SSTr2, which is consistent with the biodistribution results based on the ex vivo radioactivity measurements (Figs. 5A and 4B), $\mathrm{B}_{\max }$ values (Table 1), and in vitro uptake studies (Fig. 2A). The imaging values corrected for partial-volume effects correlated well with the tissue-sampling values (Fig. 4B). These results are consistent with SSTr2-specific small-animal PET with ${ }^{68} \mathrm{Ga}$ DOTATOC.

${ }^{68} \mathrm{Ga}$-DOTATOC levels were low in blood and other nonSSTr2-expressing organs, except the kidneys. Radioactivity in the muscle and blood was low at $0.03 \pm 0.01$ and $0.24 \pm$ $0.08 \% \mathrm{ID} / \mathrm{g}$, respectively. Conversely, organs known to express moderate levels of SSTr2 showed higher uptake of radiotracer and included the pancreas $(0.81 \pm 0.22 \% \mathrm{ID} / \mathrm{g})$, adrenal gland $(0.45 \pm 0.14 \% \mathrm{ID} / \mathrm{g})$, and pituitary gland $(0.74 \pm 0.31 \% \mathrm{ID} / \mathrm{g})$. Except for the kidneys, the highest

TABLE 1

$K_{d}$ and $B_{\max }$ Values for natGa-DOTATOC Binding to hSSTr2 Expressed by Transduced Cells

\begin{tabular}{lcccc}
\hline \multicolumn{1}{c}{ Parameter } & Jurkat-hSSTr2 $(n=4)$ & CHO-hSSTr2 $(n=7)$ & U87-hSSTr2 $(n=3)$ & C6-hSSTr2 $(n=3)$ \\
\hline $\mathrm{B}_{\max }\left(10^{5}\right.$ sites/cell $)$ & $0.36 \pm 0.04$ & $3.09 \pm 0.40$ & $2.82 \pm 0.37$ & $12.5 \pm 1.4$ \\
$\mathrm{~K}_{\mathrm{d}}(\mathrm{nM})$ & $5.26 \pm 2.73$ & $5.06 \pm 0.91$ & $6.90 \pm 1.53$ & $7.64 \pm 1.43$ \\
\hline
\end{tabular}




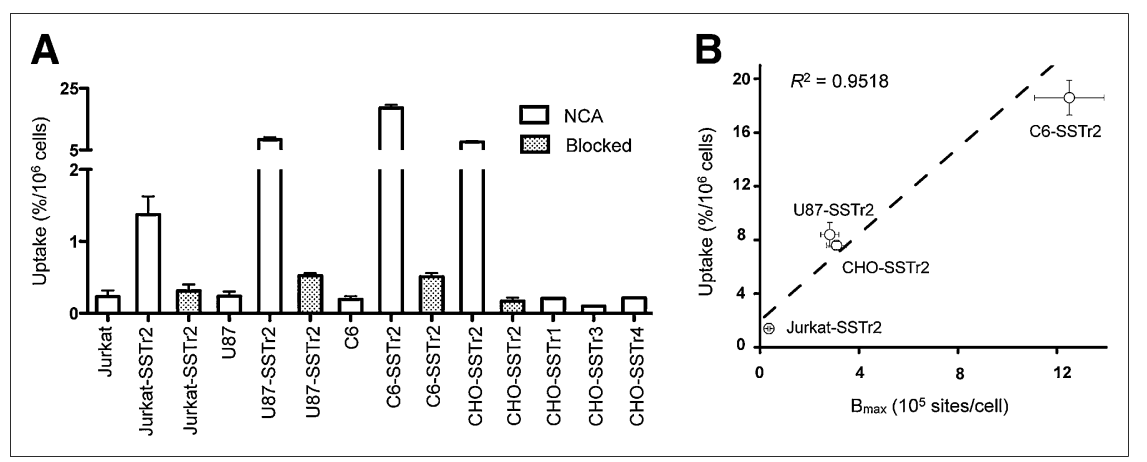

FIGURE 2. In vitro uptake of ${ }^{67} \mathrm{Ga}$-DOTATOC by hSSTr2-transduced cells. (A) Accumulation of ${ }^{67} \mathrm{Ga}$-DOTATOC in WT and hSSTrtransduced cells after $2 \mathrm{~h}$ incubation at $37^{\circ} \mathrm{C}$. nat Ga-DOTATOC or somatostatin-14 $(1 \mu \mathrm{M})$ was used in blocking experiments. (B) Correlation of ${ }^{67} \mathrm{Ga}-\mathrm{DOTATOC}$ uptake vs. $B_{\max }$ for different hSSTr2-transduced cell lines. $\mathrm{NCA}=$ no ${ }^{\text {nat }} \mathrm{Ga}$-DOTATOC or somatostatin-14 added. accumulation of radioactivity was measured in hSSTr2transduced xenografts (Fig. 5A). These values ranged from $2.27 \pm 0.44 \% \mathrm{ID} / \mathrm{g}$ for Jurkat-SSTr2, to $3.46 \pm 0.76 \% \mathrm{ID} / \mathrm{g}$ for U87-SSTr2, to $15.2 \pm 2.3 \% \mathrm{ID} / \mathrm{g}$ for C6-SSTr2. In contrast, low uptake was measured in all corresponding WT xenografts (Fig. 5A). The uptake ratio between hSSTr2transduced and nontransduced xenografts was $64 \pm 31$ for C6, $11.1 \pm 2.9$ for U87, and $8.3 \pm 3.2$ for Jurkat; comparisons to blood and muscle are also shown (Fig. 5B). These results were also consistent with the ex vivo radioautography (Supplemental Fig. 3).

There was no significant difference between the growth rates of the C6-WT or C6-SSTr2 xenografts at 9-15 d after implantation of tumor cells (Table 2). However, there was a highly significant growth delay for Jurkat-SSTR2 cells, compared with Jurkat-WT cells $(P=0.029)$, with the mean tumor weight being around 25 -fold lower. A similar but less dramatic effect was seen for the U87-SSTr2 xenografts (3-fold lower at $8 \mathrm{~d}, P=0.022$ ). Despite this, there was no correlation between ${ }^{68} \mathrm{Ga}$-DOTATOC uptake and xenograft size or age.

Linear regression analysis of SSTr2 tumor uptake $(\% \mathrm{ID} / \mathrm{g})$ versus the expression level of hSSTr2 $\left(B_{\max }\right)$ is shown in Figure 6. These results are consistent with specific, receptor-mediated uptake of ${ }^{68} \mathrm{Ga}$-DOTATOC and indicate that the expression level of hSSTr2 determines the magnitude of in vivo uptake by the transduced xenografts.

\section{DISCUSSION}

The hSSTr2 gene- ${ }^{68}$ GaDOTATOC reporter system has distinct imaging advantages over other hSSTr2-radioligand systems, other human reporter gene systems, and the HSV1tk and HSV1-tksr reporter systems (13). Compared with 3 other categories of reporter genes (fluorescent proteins, intracellular enzymes, and cell membrane transporters), hSSTr2 belongs to the category of cell membrane receptors. hSSTr2 is a transmembrane protein, and its binding domain is located on the external plasma membrane (13). The hSSTr2 gene encodes a transmembrane protein that does not require radioligand permeation of the cell membrane to bind to the receptor. We showed that this process was rapid; the halflives for binding and release from the receptor was on the order of several minutes. Interestingly, internalization of the DOTATOC ligand may be cell type-specific, because kinetic differences were observed between C6-, U87-, and CHOtransduced cells. The intracellular domain is associated with G-protein-linked signaling. Whenever an agonistic ligand binds to SSTr2, rapid internalization of the receptor-ligand complex will occur. The SSTr2 receptor will be reexpressed on the cell membrane and be ready for binding with new ligand within $24 \mathrm{~h}(21)$.

The hSSTr2 reporter gene can be compared with other human reporter genes, including the mitochondrial thymi-
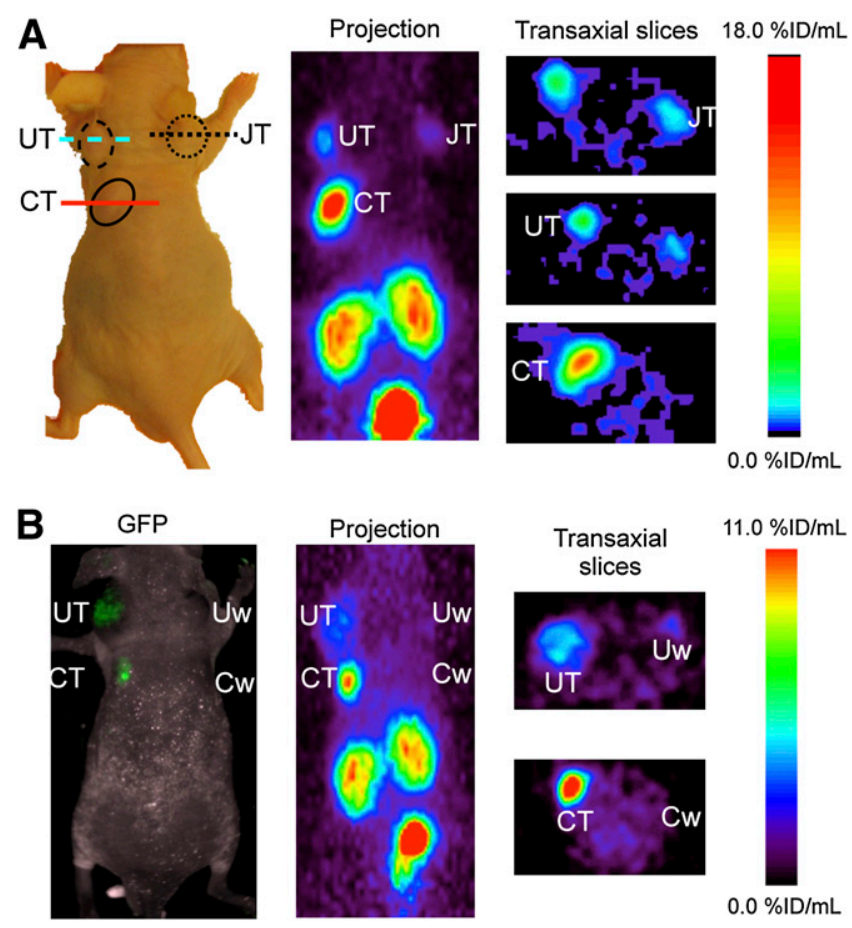

FIGURE 3. Small-animal PET and fluorescence imaging of hSSTr2transduced xenografts. (A) Optical small-animal PET projection and transaxial images of mouse with 3 transduced xenografts at $2 \mathrm{~h}$ after injection of ${ }^{68} \mathrm{Ga}$-DOTATOC. (B) GFP-fluorescence, small-animal PET projection, and transaxial images of mouse with 2 WT and 2 transduced xenografts at $2 \mathrm{~h}$ after injection of ${ }^{68} \mathrm{Ga}$-DOTATOC. Radioactivity in kidneys and bladder is visualized in projection images. CT = C6-SSTr2; CW = C6-WT; JT = Jurkat-SSTr2; UT = U87-SSTr2; $\mathrm{UW}=\mathrm{U} 87-\mathrm{WT}$. 
FIGURE 4. Small-animal PET tumor uptake of ${ }^{68} \mathrm{Ga}-D O T A T O C$. (A) Uptake $(\% \mathrm{ID} / \mathrm{mL})$ derived from small-animal PET at 1 and $2 \mathrm{~h}$ after injection of ${ }^{68} \mathrm{Ga}$-DOTATOC. (B) Correlation of uptake values derived from small-animal PET and biodistribution for ${ }^{68} \mathrm{Ga}$ DOTATOC. CT = C6-SSTr2; CW = C6-WT; JT = Jurkat-SSTr2; Jw = Jurkat-WT; UT = U87-SSTr2; Uw = U87-WT.

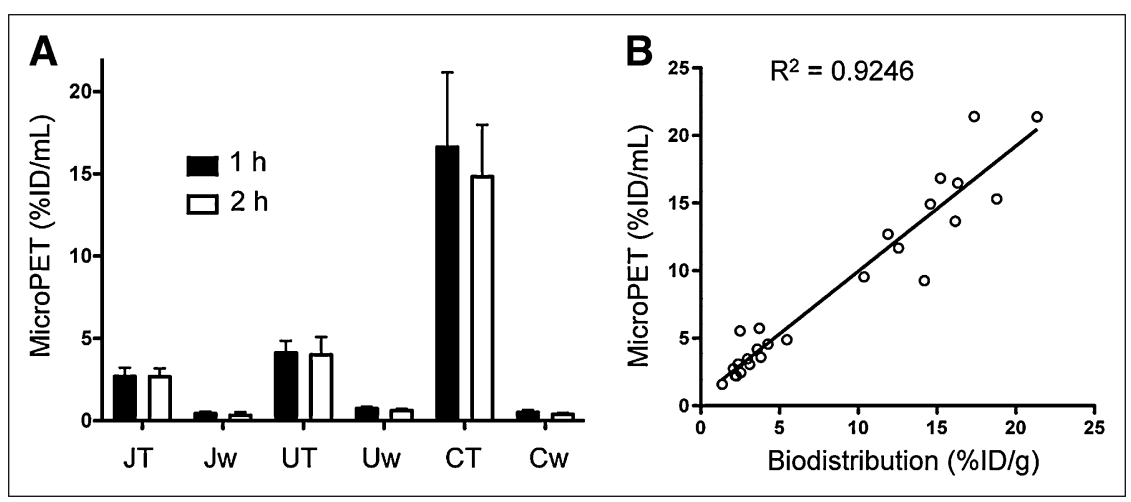

dine kinase 2 (22), sodium iodide symporter (23), and norepinephrine transporter (24) genes. A comparison of the hSSTr2-radioligand systems published in the literature is provided in Table 3, and a summary of other published reporter systems studied in our laboratory is provided in Supplemental Table 1. The comparisons in Table 3 and Supplemental Table 1 demonstrate the potential advantages of the hSSTr2 gene- ${ }^{68} \mathrm{Ga}$-DOTATOC reporter system. A significant time dependence for optimal transduced-tonontransduced tumor uptake ratios has been demonstrated for other reporter-radioligand systems, and optimal images are obtained at late imaging times $(22,24)$. However, radiolabeled somatostatin analogs (small peptide) generally display rapid accumulation and can be excreted rapidly as well—especially true for ${ }^{68} \mathrm{Ga}$-DOTATOC. Rapid uptake in the reporter-transduced xenografts and rapid excretion of nonbound ligand were observed. As a result, ${ }^{68} \mathrm{Ga}-$ DOTATOC showed high transduced-to-nontransduced tumor uptake ratios at early imaging times $(1 \mathrm{~h}$ after injection), and image quality at $2 \mathrm{~h}$ after injection did not improve significantly, reflecting rapid binding and high affinity in the setting of rapid renal clearance. ${ }^{68} \mathrm{Ga}$-DOTATOC uptake in reporter-transduced xenografts was directly proportional to hSSTr2 expression levels in the xenografts, indicating that early PET with ${ }^{68} \mathrm{Ga}$-DOTATOC could serve as a basis for the noninvasive quantification of hSSTr2 gene expression.
Thus, the ${ }^{68} \mathrm{Ga}$-DOTATOC-hSSTr2 system has potential for being an ideal human reporter gene system for translation to clinical studies.

Although the hSSTr2 gene was originally described as a promising reporter gene in 1999 (14) and again in 2005 (17) (Table 2), image quality remained suboptimal using ${ }^{111}$ In-DTPA-octreotide, ${ }^{99 m} \mathrm{Tc}-\mathrm{P} 829,{ }^{188} \mathrm{Re}-\mathrm{P} 829,{ }^{99 \mathrm{~m} T c-}$ P2045, or ${ }^{94 \mathrm{~m}} \mathrm{Tc}-$ demotate-1 radioligands (Table 3). This has now changed significantly with the availability of ${ }^{68} \mathrm{Ga}-$ DOTATOC. DOTATOC is a peptide-chelate conjugate originally designed for radiotherapy of SSTr2-expressing tumors (18). It has been classified as a receptor agonist and has undergone extensive clinical testing in both Europe (3) and the United States (25) and is being developed as a clinical imaging and targeted radiotherapeutic agent. GalliumDOTATOC has been reported as an SSTr2- or SSTr5-selective ligand; it displaces the binding of the panspecific ligand ${ }^{125}$ I-Tyr $^{11}$-SST14 to SSTr1-SSTr5 with an inhibitory concentration of $50 \%\left(\mathrm{IC}_{50}\right)$ of $>1,000$ for $\mathrm{SSTr} 1,2.5$ for SSTr2, 613 for SSTr3, >1,000 for SSTr4, and $73 \mathrm{nM}$ for SSTr5 (26). Although direct $\mathrm{K}_{\mathrm{d}}$ values have not been determined for these analogs, our calculated binding affinity of 5-7 $\mathrm{nM}$ for gallium-DOTATOC is consistent with the $2.5 \mathrm{nM} \mathrm{IC} \mathrm{I}_{50}$ value for ${ }^{125}{ }^{2}-\mathrm{Tyr}^{11}$-SST14 binding. Other somatostatin analogs such as vapreotide and lanreotide are SSTr2-, SSTr3-, and SSTr5-specific, with low nanomolar binding affinities to

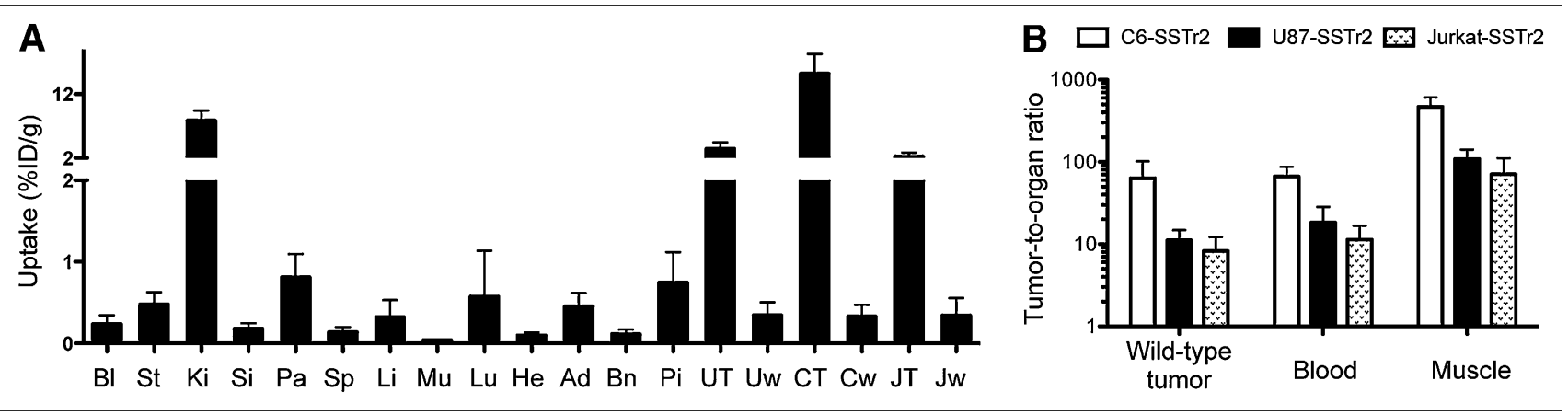

FIGURE 5. ${ }^{68} \mathrm{Ga}$-DOTATOC biodistribution studies. (A) Biodistribution of ${ }^{68} \mathrm{Ga}-\mathrm{DOTATOC}(\% \mathrm{ID} / \mathrm{g} \pm \mathrm{SD}$ ) in hSSTr2-transduced tumorbearing nude mice at $2 \mathrm{~h}$ after injection. (B) ${ }^{68} \mathrm{Ga}-\mathrm{DOTATOC}$ uptake ratios for hSSTr2-transduced xenograft and normal organs. Ad = adrenal; $\mathrm{BI}=$ blood; $\mathrm{Bn}=$ bone; CT = C6-SSTr2; Cw = C6-WT; He = heart; JT = Jurkat-SSTr2; Jw = Jurkat-WT; Ki = kidney; Li = liver; $\mathrm{Mu}=$ muscle; $\mathrm{Pa}=$ pancreas; $\mathrm{Pi}=$ pituitary; $\mathrm{Si}=$ small intestines; $\mathrm{Sp}=$ spleen; $\mathrm{St}=$ stomach; UT = U87-SSTr2; Uw = U87-WT. 
TABLE 2

Effect of SSTr2 Expression on Xenograft Growth in Athymic Mice

\begin{tabular}{|c|c|c|c|c|c|}
\hline \multirow[b]{2}{*}{ Cell line } & \multirow[b]{2}{*}{ Time after inoculation (d) } & \multirow[b]{2}{*}{ WT tumors, mass $(\mathrm{mg}) \pm \mathrm{SD}$} & \multicolumn{2}{|c|}{ SSTr2 transfected tumors } & \multirow[b]{2}{*}{$P$} \\
\hline & & & Mass $(\mathrm{mg}) \pm \mathrm{SD}$ & $\mathrm{B}_{\max }($ sites/cell) & \\
\hline C6 & $9-10$ & $47 \pm 1$ & $56 \pm 18$ & $1,250,000$ & 0.54 \\
\hline C6 & 14-15 & $44 \pm 40$ & $32 \pm 13$ & $1,250,000$ & 0.41 \\
\hline U87 & $8-9$ & $92 \pm 64$ & $34 \pm 28$ & 282,000 & 0.022 \\
\hline Jurkat & 35 & $630 \pm 442$ & $23 \pm 6$ & 35,800 & 0.029 \\
\hline
\end{tabular}

these receptor subtypes (27). The FDA-approved P829 ligand has a similar SSTr2-, SSTr3-, and SSTr5-binding profile, with $\mathrm{IC}_{50}$ values of $2.5,1.5$, and 2.0 , respectively (28). On the basis of SSTr binding affinities, gallium-DOTATOC is the more optimal agent for imaging SSTr2 in vivo. Consistent with these findings, ${ }^{68} \mathrm{Ga}$-DOTATOC has been used successful in imaging neuroendocrine tumors in patients.

Apart from being SSTr2-specific, ${ }^{68} \mathrm{Ga}$-DOTATOC can be rapidly prepared with the generator-produced $P E T$ radionuclide ${ }^{68} \mathrm{Ga}$ (half-life, $68.3 \mathrm{~min}$; maximum energy of the positron electron, $1.89 \mathrm{MeV}, 89 \%$ ). This isotope has a high abundance of $\beta^{+}$particles, which can be quantified by clinical PET cameras. The short half-life is ideally suited to the rapid blood clearance of the ligand and reduces patient radiation dose. Because ${ }^{68} \mathrm{Ga}$ is a generator-produced radionuclide, it can be produced and used at nuclear medicine facilities with no onsite cyclotron, using a simple kit preparation procedure.

Several issues not addressed in this study relate to the potential biologic effects of transducing a cell membrane signaling receptor on the transduced cells. In vitro, activation of SSTr2 on tumor cells results in cell growth arrest, whereas activation of SSTr5 results in cell proliferation. Moreover, selective SSTr2 and selective SSTr5 agonists counteract and antagonize each other $(29,30)$. For carcinoid tumors, this counteraction seems to explain why SSTr2 agonists can reduce symptomatic effects but only some tumors show growth responses. Moreover, for somatotropinomas, Taboada et al. (31) have shown that patients who have high SSTr2-SSTr5 messenger RNA tumor levels respond better to octreotide therapy than those with low ratios. In vivo animal studies have also shown that SSTr2-transfected xenografts are more sensitive to somatostatin treatment $(32,33)$, and the SSTr2-transfected tumors grow more slowly than WT tumors. For example, Vernejoul et al. observed that endogenous somatostatin was able to suppress the growth after in vivo SSTr2 gene transfer to orthotopically implanted pancreatic tumors (32).

We observed variable effects of SSTr2 transduction on xenograft growth rates. C6-SSTr2 xenografts, which had high SSTr2 expression in vitro and high ${ }^{68} \mathrm{Ga}$-DOTATOC uptake in vivo, did not significantly differ in the tumor size from C6-WT xenografts. Compared with U87-WT xenografts, U87-SSTr2 xenografts, which had moderate SSTr2 expression in vitro and moderate ${ }^{68} \mathrm{Ga}$-DOTATOC uptake in vivo, showed a significant delay in tumor growth at $8 \mathrm{~d}$ after implantation. Finally, compared with nontransduced, WT Jurkat xenografts, Jurket-SSTr2 xenografts, which had the lowest SSTr2 expression in vitro and moderate ${ }^{68} \mathrm{Ga}-$ DOTATOC uptake in vivo, demonstrated a large and significant growth delay (tumor size) at $35 \mathrm{~d}$ after implantation. These results suggest considerable intertumor variability with respect to the ability of endogenous somatostatin to suppress tumor growth.

Because SSTr2 gene therapy can dramatically affect tumor growth rate, a constitutively expressed SSTr2 reporter gene may not be widely applicable for monitoring tumor trafficking, growth, and metastases. For similar reasons, the use of an inducible SSTr2 reporter gene to monitor cell signaling and function is likely to be compromised by endogenous somatostatin ligands. For example, the SSTr2 reporter gene is unlikely to be useful for monitoring $\mathrm{T}$ cells in vivo, because $\mathrm{T}$ cells are known to express SSTr2 and activation of this receptor leads to the suppression of $\gamma$ interferon (34) secretion. In activated T cells, there is an upregulation of SSTr5 (35), which when activated in tumor cells abrogates the effects of SSTr2 activation (30). Because we and others have shown that SSTr2 transfection of tumor cells can slow their growth in vivo, it is highly plausible that

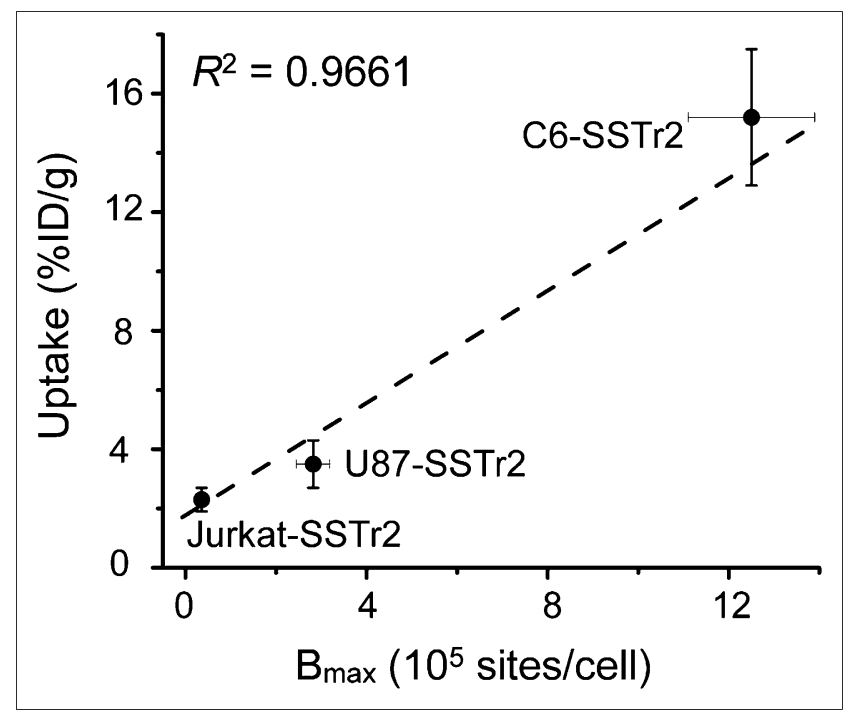

FIGURE 6. Correlation of in vivo tumor uptake of ${ }^{68} \mathrm{Ga}$-DOTATOC $(\% \mathrm{ID} / \mathrm{g})$ and in vitro hSSTr2 expression $\mathrm{B}_{\max }$. 
TABLE 3

Comparison of Radioligands for Imaging Human SSTr Reporter Gene

\begin{tabular}{|c|c|c|c|c|c|}
\hline \multirow[b]{2}{*}{ Transduced xenograft } & \multirow[b]{2}{*}{ Ligand } & \multicolumn{3}{|c|}{ Uptake } & \multirow[b]{2}{*}{ References } \\
\hline & & $\%$ dose $/ \mathrm{cm}^{3}$ & $\begin{array}{c}\text { Ratio of } \\
\text { transduced to WT }\end{array}$ & $\begin{array}{c}\text { Ratio of } \\
\text { transduced to muscle }\end{array}$ & \\
\hline SKOV3 & ${ }^{111}$ In-DTPA-octreotide & $32(4 h)^{\star \dagger}$ & $38(4 h)^{\star \dagger}$ & $30(4 \mathrm{~h})$ & Rogers et al. (14) \\
\hline \multirow[t]{2}{*}{$A-427$} & 99mTc-P829 & $2.5(5 \mathrm{~h})^{\star}+$ & $4(3 \mathrm{~h})^{\star \dagger}$ & 4 (3 h) & Zinn et al. (16) \\
\hline & ${ }^{188} \mathrm{Re}-\mathrm{P} 829$ & $2.2(5 \mathrm{~h})^{\star \dagger}$ & & & \\
\hline SKOV3 & 99mTc-P2045 & $4.0(2 \mathrm{~h})^{\star \dagger}$ & $12.2(5 \mathrm{~h})^{\star \dagger}$ & ND & Chaudhuri et al. (38) \\
\hline$A-427$ & 94mTc-demotate 1 & & $>5(2 \mathrm{~h})^{\star \ddagger}$ & 10 (1 h), 20(2 h) & Rogers et al. (17) \\
\hline HT1080 & ${ }^{111}$ In-DTPA-octreotide & $1.7(24 \mathrm{~h})^{\star \dagger}$ & $14(24 \mathrm{~h})^{\star}$ & $42(24 \mathrm{~h})$ & Yang et al. (39) \\
\hline MDA-MB-435 & ${ }^{111}$ In-DTPA-octreotide & $1.8(24 \mathrm{~h})^{\star \dagger}$ & 18 (24 h) *† & 27 (24 h) & Singh et al. (40) \\
\hline C6 & ${ }^{68} \mathrm{Ga}-\mathrm{DOTATOC}$ & $15(2 \mathrm{~h})^{\star \ddagger}$ & $64(2 h)^{\star \ddagger}$ & $\sim 500(2 \mathrm{~h})$ & Current work \\
\hline \multicolumn{6}{|l|}{$\begin{array}{l}{ }^{\star} \text { Mouse. } \\
{ }^{\dagger} \gamma \text {-camera values. } \\
{ }^{\ddagger} \text { PET values. } \\
\text { ND }=\text { not determined. }\end{array}$} \\
\hline
\end{tabular}

SSTr2-transfected $\mathrm{T}$ cells will demonstrate phenotypic alterations associated with activation of hSSTr2-mediated signaling by endogenous somatostatin.

To avoid endogenous SSTr2 signaling in SSTr2 reportertransduced cells, modifications of the hSSTr2 gene are necessary to abrogate its signal transduction function without compromising its ligand-binding receptor function. Such a strategy has been shown to be successful for the dopamine 2 receptor (36). Recently, Han et al. showed that hSSTr2activated signaling can be eliminated by selective truncation of the intracellular domain of the receptor (37). They developed a mutated hSSTr2 gene, HA-SSTr $2 \Delta 314$, and showed that this truncation of the intracellular domain eliminated SSTr2-mediated intracellular signaling, as measured by the absence of effects on cAMP, cGMP, and proliferation, but does not alter ${ }^{111}$ In-DTPA-octreotide binding to the receptor. Their in vivo SPECT study of xenografts transduced with the truncated receptor (HA-SSTr2 3314 ) yielded results similar to those of xenografts transduced with the WT receptor (37).

\section{CONCLUSION}

Our studies show that high specificity and sensitivity for imaging hSSTr2 reporter gene expression is obtained with ${ }^{68}$ Ga-DOTATOC and that, compared with other SSTr2binding radioligands, it provides high transduced-to-nontransduced (target-to-background) radioactivity ratios at early imaging times. The hSSTr2- ${ }^{68} \mathrm{Ga}$-DOTATOC reporter system is a promising combination for translation to clinical studies, providing that endogenous SSTr2 signaling does not significantly affect the biology of the transduced cells. Alternatively, the application of a truncated hSSTr2 gene, such as HA-SSTr2 $\Delta 314$, may be more desirable.

\section{ACKNOWLEDGMENTS}

We thank Dr. Pat Zanzonico and Valerie Longo for imaging support, Dr. Ekaterina Moroz for technical sup- port, and Dr. Friedrich Raulf of Novartis (Basle, Switzerland) for kindly supplying SSTr-transfected CHO cells. We also appreciate Dr. Graeme Bell (University of Chicago, Chicago, IL) for kindly supplying the hSSTr2 gene. This work was supported by NIH grant P50-CA84638. The Memorial Sloan-Kettering Cancer Center Small Animal Imaging Core Facility was supported by NIH SmallAnimal Imaging Research Program grant R24 CA83084 and NIH Center grant P30 CA08748.

\section{REFERENCES}

1. Reubi JC. Peptide receptors as molecular targets for cancer diagnosis and therapy. Endocr Rev. 2003;24:389-427.

2. van der Lely AJ, de Herder WW, Krenning EP, Kwekkeboom DJ. Octreoscan radioreceptor imaging. Endocrine. 2003;20:307-311.

3. Bodei L, Ferone D, Grana CM, et al. Peptide receptor therapies in neuroendocrine tumors. J Endocrinol Invest. 2009;32:360-369.

4. Patel YC. Somatostatin and its receptor family. Front Neuroendocrinol. 1999; 20:157-198.

5. Susini C, Buscail L. Rationale for the use of somatostatin analogs as antitumor agents. Ann Oncol. 2006;17:1733-1742.

6. Danesi R, Agen C, Benelli U, et al. Inhibition of experimental angiogenesis by the somatostatin analogue octreotide acetate (SMS 201-995). Clin Cancer Res. 1997;3:265-272.

7. Florio T, Morini M, Villa V, et al. Somatostatin inhibits tumor angiogenesis and growth via somatostatin receptor-3-mediated regulation of endothelial nitric oxide synthase and mitogen-activated protein kinase activities. Endocrinology. 2003;144:1574-1584.

8. Mentlein R, Eichler O, Forstreuter F, Held-Feindt J. Somatostatin inhibits the production of vascular endothelial growth factor in human glioma cells. Int $J$ Cancer. 2001;92:545-550.

9. Florio T. Molecular mechanisms of the antiproliferative activity of somatostatin receptors (SSTRs) in neuroendocrine tumors. Front Biosci. 2008;13:822840 .

10. Ludvigsen E, Stridsberg M, Taylor JE, Culler MD, Oberg K, Janson ET. Subtype selective interactions of somatostatin and somatostatin analogs with sst1, sst2, and sst5 in BON-1 cells. Med Oncol. 2004;21:285-295.

11. Gabriel M, Oberauer A, Dobrozemsky G, et al. ${ }^{68} \mathrm{Ga}$-DOTA-Tyr ${ }^{3}$-octreotide PET for assessing response to somatostatin-receptor-mediated radionuclide therapy. J Nucl Med. 2009;50:1427-1434.

12. Henze M, Schuhmacher J, Hipp P, et al. PET imaging of somatostatin receptors using $\left[{ }^{68} \mathrm{Ga}\right]$ DOTA-D-Phe ${ }^{1}-\mathrm{Tyr}^{3}$-octreotide: first results in patients with meningiomas. J Nucl Med. 2001;42:1053-1056.

13. Serganova I, Ponomarev V, Blasberg R. Human reporter genes: potential use in clinical studies. Nucl Med Biol. 2007;34:791-807. 
14. Rogers BE, McLean SF, Kirkman RL, et al. In vivo localization of [ $\left.{ }^{111} \mathrm{In}\right]-\mathrm{DTPA}-\mathrm{D}-$ Phe1-octreotide to human ovarian tumor xenografts induced to express the somatostatin receptor subtype 2 using an adenoviral vector. Clin Cancer Res. 1999;5:383-393.

15. Kundra V, Mannting F, Jones AG, Kassis AI. Noninvasive monitoring of somatostatin receptor type 2 chimeric gene transfer. J Nucl Med. 2002;43:406-412.

16. Zinn KR, Buchsbaum DJ, Chaudhuri TR, Mountz JM, Grizzle WE, Rogers BE. Noninvasive monitoring of gene transfer using a reporter receptor imaged with a highaffinity peptide radiolabeled with ${ }^{99 \mathrm{~m}} \mathrm{Tc}$ or ${ }^{188}$ Re. J Nucl Med. 2000;41:887-895.

17. Rogers BE, Parry JJ, Andrews R, Cordopatis P, Nock BA, Maina T. MicroPET imaging of gene transfer with a somatostatin receptor-based reporter gene and 94m Tc-demotate 1. J Nucl Med. 2005;46:1889-1897.

18. Albert R, Smith-Jones P, Stolz B, et al. Direct synthesis of [DOTA-DPhe ${ }^{1}$ ]octreotide and [DOTA-DPhe ${ }^{1}, \mathrm{Tyr}^{3}$ ]-octreotide (SMT487): two conjugates for systemic delivery of radiotherapeutical nuclides to somatostatin receptor positive tumors in man. Bioorg Med Chem Lett. 1998;8:1207-1210.

19. Serganova I, Doubrovin M, Vider J, et al. Molecular imaging of temporal dynamics and spatial heterogeneity of hypoxia-inducible factor- 1 signal transduction activity in tumors in living mice. Cancer Res. 2004;64:6101-6108.

20. Burns AA, Vider J, Ow H, et al. Fluorescent silica nanoparticles with efficient urinary excretion for nanomedicine. Nano Lett. 2009;9:442-448.

21. Waser B, Tamma ML, Cescato R, Maecke HR, Reubi JC. Highly efficient in vivo agonist-induced internalization of sst 2 receptors in somatostatin target tissues. J Nucl Med. 2009;50:936-941.

22. Tjuvajev JG, Doubrovin M, Akhurst T, et al. Comparison of radiolabeled nucleoside probes (FIAU, FHBG, and FHPG) for PET imaging of HSV1-tk gene expression. J Nucl Med. 2002;43:1072-1083.

23. Che J, Doubrovin M, Serganova I, Ageyeva L, Zanzonico P, Blasberg R. hNISIRES-eGFP dual reporter gene imaging. Mol Imaging. 2005;4:128-136.

24. Moroz MA, Serganova I, Zanzonico P, et al. Imaging hNET reporter gene expression with ${ }^{124}$ I-MIBG. J Nucl Med. 2007;48:827-836.

25. Bushnell D. Treatment of metastatic carcinoid tumors with radiolabeled biologic molecules. J Natl Compr Canc Netw. 2009;7:760-764.

26. Reubi JC, Schar JC, Waser B, et al. Affinity profiles for human somatostatin receptor subtypes SST1-SST5 of somatostatin radiotracers selected for scintigraphic and radiotherapeutic use. Eur J Nucl Med. 2000;27:273-282.

27. Patel YC, Srikant CB. Subtype selectivity of peptide analogs for all five cloned human somatostatin receptors (hsstr 1-5). Endocrinology. 1994;135:2814-2817.

28. Virgolini I, Leimer M, Handmaker H, et al. Somatostatin receptor subtype specificity and in vivo binding of a novel tumor tracer, ${ }^{99 \mathrm{~m}} \mathrm{Tc}-\mathrm{P} 829$. Cancer Res. 1998;58:1850-1859.
29. Barbieri F, Pattarozzi A, Gatti M, et al. Somatostatin receptors 1 , 2, and 5 cooperate in the somatostatin inhibition of $\mathrm{C} 6$ glioma cell proliferation in vitro via a phosphotyrosine phosphatase-eta-dependent inhibition of extracellularly regulated kinase-1/2. Endocrinology. 2008;149:4736-4746.

30. Zatelli MC, Tagliati F, Taylor JE, Rossi R, Culler MD, degli Uberti EC. Somatostatin receptor subtypes 2 and 5 differentially affect proliferation in vitro of the human medullary thyroid carcinoma cell line tt. J Clin Endocrinol Metab. 2001;86:2161-2169.

31. Taboada GF, Luque RM, Neto LV, et al. Quantitative analysis of somatostatin receptor subtypes (1-5) gene expression levels in somatotropinomas and correlation to in vivo hormonal and tumor volume responses to treatment with octreotide LAR. Eur J Endocrinol. 2008;158:295-303.

32. Vernejoul F, Faure P, Benali N, et al. Antitumor effect of in vivo somatostatin receptor subtype 2 gene transfer in primary and metastatic pancreatic cancer models. Cancer Res. 2002;62:6124-6131.

33. Zhou T, Xiao X, Xu B, Li H, Zou Y. Overexpression of SSTR2 inhibited the growth of SSTR2-positive tumors via multiple signaling pathways. Acta Oncol. 2009;48:401-410.

34. Elliott DE, Li J, Blum AM, Metwali A, Patel YC, Weinstock JV. SSTR2A is the dominant somatostatin receptor subtype expressed by inflammatory cells, is widely expressed and directly regulates T cell IFN-gamma release. Eur J Immunol. 1999;29:2454-2463.

35. Talme T, Ivanoff J, Hagglund M, Van Neerven RJ, Ivanoff A, Sundqvist KG. Somatostatin receptor (SSTR) expression and function in normal and leukaemic T-cells. Evidence for selective effects on adhesion to extracellular matrix components via SSTR2 and/or 3. Clin Exp Immunol. 2001;125:71-79.

36. MacLaren DC, Gambhir SS, Satyamurthy N, et al. Repetitive, non-invasive imaging of the dopamine D2 receptor as a reporter gene in living animals. Gene Ther. 1999;6:785-791.

37. Han L, Yang D, Kundra V. Signaling can be uncoupled from imaging of the somatostatin receptor type 2. Mol Imaging. 2007;6:427-437.

38. Chaudhuri TR, Rogers BE, Buchsbaum DJ, Mountz JM, Zinn KR. A noninvasive reporter system to image adenoviral-mediated gene transfer to ovarian cancer xenografts. Gynecol Oncol. 2001;83:432-438.

39. Yang D, Han L, Kundra V. Exogenous gene expression in tumors: noninvasive quantification with functional and anatomic imaging in a mouse model. Radiology. 2005;235:950-958.

40. Singh SP, Yang D, Ravoori M, Han L, Kundra V. In vivo functional and anatomic imaging for assessment of in vivo gene transfer. Radiology. 2009; 252:763-771. 